\title{
CRITICAL UNDRAINED SHEAR STRENGTH OF LOOSE-MEDIUM SAND-SILT MIXTURES UNDER MONOTONIC LOADINGS
}

\author{
Mohamed Bensoula, Hanifi Missoum, Karim Bendani \\ Laboratory of Construction, Transports and Environment Protection (LCTPE), University of Mostaganem, Mostaganem, \\ Algeria; e-mail : bensoulamoh@hotmail.com; hanifimissoum@yahoo.fr; bendanik@yahoo.fr
}

\begin{abstract}
Empirical relationships are developed for estimating the undrained critical shear strength based on experimental triaxial tests under monotonic loadings. The effect of fines content on the undrained shear strength is analyzed for different combinations of density states. The parametric study indicates that in terms of the soil void ratio and fines content properties, the undrained critical shear strength may increase, or decrease as the amount of fines content increases, consequently showing vulnerability to liquefaction influenced by the fines content percentage. A series of monotonic undrained triaxial tests have been undertaken on a reconstituted saturated sand-silt mixtures specimen. Beyond $30 \%$ of fines content, it is shown that a fraction of silt participates in the soil skeleton chain force. In this context, the concept of the equivalent intergranular void ratio may be an appropriate parameter to express the critical shear strength of the soil under investigation. This parameter is able to control the undrained shear strength of non plastic silt and sand mixtures for different density states.
\end{abstract}

Keywords: sand, silt, density, undrained, strength

\section{List of symbols}

$C_{u}, C_{c}$ - coefficient of uniformity and curvature, respectively

$D_{r}, D_{r}^{*}$ - initial and equivalent relative density, respectively

$D_{i}$ - soil diameter at which $i \%$ of the soil weight is finer

$e, e_{\max }, e_{\min }, e_{s}, e^{*}-$ global, maximum, minimum, intergranular and equivalent void ratio

$e_{\max , c s}, e_{\min , c s}-$ maximum and minimum void ratio of clean sand

$F_{c}, F_{\text {thre }}$ - content of fines and threshold fines

$G_{s}$ - specific gravity of soil grain

$I_{p}$ - plasticity index

$k$ - soil parameter

$M$ - slope of critical state line

$p^{\prime}, p_{c r}^{\prime}, p_{s}^{\prime}$ - effective mean stress, effective mean stress at critical and steady state

$q, q_{c r}, q_{s}$ - deviatoric stress, deviatoric stress at critical and steady state

$r$ - soil size ratio

$S_{\text {ucr }}$ - undrained critical shear strength

$\alpha$ - silt fraction parameter

$\varepsilon_{a}-$ axial strain

$\phi_{s}$ - mobilized angle of inter-particle friction at the steady state

$\gamma_{d}-$ solid dry density

$\sigma_{c}-$ confining pressure 


\section{Introduction}

Northern Algeria is located at the tectonic plate boundary (ruptured fault). Due to this situation, many earthquakes occurred in the region. The history of the recent seismic activity in Algeria shows that, over the last twenty years, the country has witnessed the Mascara earthquake in 1994 (M: 5.6), the Algiers earthquake in1996 (M: 5.7), the Ain-Temouchent earthquake in 1999 (M: 5.8), the Beni-Ouartilane earthquake in 2000 (M: 5.4) and the Boumerdes earthquake in 2003 (M: 6.9).These earthquakes caused major structural damages to constructions and dramatic human losses. In these events, a numerous cases of ejection onto the ground surface level of great masses of sandy soils and large displacements of some equipment foundations were observed.

The region of Mostaganem belongs to the northern part of the country. Moreover, it lies on geological layers of vast deposits of silty sand and where the phreatic water table is not deeper. These conditions enhance the liquefaction phenomena. Facing the soil failure phenomenon, there is a need to characterize this granular media as an engineering material.

Under undrained conditions, the shear resistance of sandy soils may decrease by either monotonic (e.g. erosion at the toe of a slope, reservoir filling, rapid sediment accumulation) or dynamic (e.g. earthquake, vibration or blast) loadings, leading to phenomena of liquefaction. The pore water in a saturated sandy soil will increase due to the tendency of the volume contraction if the drainage of the water is impeded. This results in a lower effective stress and, consequently, the reduction of soil strength.

Several liquefaction flow failures are triggered by static and cyclic mechanisms. Liquefaction may lead to catastrophic failure, if the shear resistance of a soil vulnerable to liquefaction drops below the existing initial static load (e.g. driving shear stress in a slope). Many cases of static liquefaction flow failures were reported by Olson and Stark (2003). The undrained shear strength mobilized of sandy soils during flow failures and liquefaction is an essential parameter in undrained stability analysis in order to evaluate the occurrence of flow deformation. A right estimation of the undrained liquefied strength is of paramount importance for the design of soil structures such as earth dams, bridge supports and building foundations in the aim to protect them against liquefaction flow failure.

The understanding of soil liquefaction is continuously being revised as long as new in-field and laboratory observations are discovered. Obvious evidences had significantly influenced the research trend in investigating the liquefaction of natural sandy soil deposits. The effects of fines on mechanical behaviour of sand matrix soil are not yet fully understood. Therefore, the present challenge is to improve fundamental research on the mechanical behaviour of soils susceptible to liquefy in order to unify the treatment of such soils.

The presence of fines may either increase or decrease liquefaction vulnerability. Many contributions tried to characterize the influence of fines onto liquefaction behaviour of sand matrix soils. The Chinese criteria (Wang, 1979) are the well-known liquefaction susceptibility identification. It is essentially based on in-field observations. This criterion has experienced many revisions, but it still forms the basic principles and guidelines for many codes of practices. Nevertheless, new recent evidences show some inadequacy and deviation due to the presence of fines, mainly plastic fines. Due to discrepancies in the research results in laboratory and post-liquefaction events, many researchers agreed that such procedures should be discontinued and should be reviewed in a general context (Prakash and Puri, 2010).

Silty sands are the most common type of soils involved in flow liquefaction events. Static and earthquake induced liquefaction failure case events were cited by Yamamuro and Lade (1998). Several studies have been conducted on the influence of fine particles on liquefaction behaviour of sandy soils. Seed et al. (1983) observed that some types of soil with fine content may be highly susceptible to liquefaction vulnerability. Then, after performing several tests, Yamamuro 
and Lade (1997) showed that the increase of silt in sand leads to the decrease in the undrained shear resistance of silty sand at a constant total void ratio.

The behaviour of clean sand is different from sand silt mixtures. There are contradictory conclusions over this difference as some concluded that silt in the sand matrix reduces undrained shear resistance of sandy-soil mixtures, Chang et al. (1982), while other researchers had the opposite opinion, Troncoso and Verdugo (1985), and Vaid (1994).

Hence, based upon contradictory results presented in the literature, the fines content of a sandy soil does not provide a unified behavioural trend, although recent advances have been achieved on this area of research. This is still non unified and controversial.

The stability of structures founded on a liquefied soil depends on post-liquefaction of the soil shear strength. The strength of soils at the phase transition has important influence for engineering design (Ishihara, 1993). Consequently, it is important to clarify the main parameters that influence substantially the shear resistance and to provide some principles in the design process. Yamamuro and Lade (1997) showed that the intergranular void ratio $e_{s}$ probably can control the undrained resistance of sand-silt mixtures. $e_{s}$ represents the space within sand grains and can be computed (Thevanayagam and Mohan, 2000) as

$$
e_{s}=\frac{e+F_{c}}{1-F_{c}}
$$

where $e$ is the global void ratio and $F_{c}$ is the fines content (the ratio of silt weight to the total sample weight).

Then, Thevanayagam et al. (2002) gave a modified parameter and stated that beyond a certain value of $F_{c}$ (threshold value), a fraction of silt participate in the soil skeleton chain force, and then introduced a new parameter defined as an equivalent intergranular void ratio. This parameter is able to influence the undrained shear resistance of non plastic silt and sand mixtures, and is given by the following equation:

$$
e^{*}=\frac{e+\alpha F_{c}}{1-\alpha F_{c}}
$$

where $e^{*}$ is the equivalent void ratio and $\alpha$ is a parameter determining the silt fraction which does participate in the soil strength skeleton. When $\alpha=1$, the equivalent granular void ratio is reduced to the intergranular void ratio.

This paper presents a parametric study for estimating the undrained liquefied shear strength of silty sand using state parameters and geotechnical properties of the mixtures. This work is conducted in order to investigate the effects of non plastic silty fines content on the undrained liquefied shear strength of the silt sand mixture. Our main aim in this study is focused on introducing relationships expressing the critical undrained shear resistance in terms of different soil parameters of Mostaganem sandy soil at different relative densities and different fines content up to $40 \%$.

In the objective to achieve this aim, a series of monotonic undrained triaxial tests have been undertaken on a reconstituted saturated sand-silt mixtures specimen.

\section{Materials tested}

Soil from coastal region of Mostaganem site was collected at different depths; it shows that the silty fines content does not exceed merely 30\%. Meanwhile, in our experiments sand and silt were separated and used to form specimen under investigation. The specific gravity of sand and silt was 2.67 and 2.69, respectively. The tests were conducted on the mixtures of collected sand and silt. The plastic limit and liquid limit of the silt were $20 \%$ and $25 \%$, respectively. Since 
most static liquefaction and earthquake induced liquefaction occurred in silty sand and sandy silt, different silt contents ranging from $0 \%$ to $40 \%$ were mixed to Mostaganem sand and then used in the tests. As well, liquefaction vulnerability was highly affected by the relative density of the soil (Yamamuro and Kelly, 2001; Maheshwari and Patel, 2010). In this work, different soil density states have been studied. The geotechnical properties of the soil used in this work are presented in Table 1.

Table 1. Geotechnical properties of sand-silt mixtures

\begin{tabular}{|c|c|c|c|c|c|c|}
\hline $\begin{array}{c}\text { Index } \\
\text { proper- } \\
\text { ties }\end{array}$ & $\begin{array}{c}\text { Clean } \\
\text { sand } \\
\left(0 \% F_{c}\right)\end{array}$ & $\begin{array}{c}\text { Silty } \\
\text { sand } \\
\left(10 \% F_{c}\right)\end{array}$ & $\begin{array}{c}\text { Silty } \\
\text { sand } \\
\left(20 \% F_{c}\right)\end{array}$ & $\begin{array}{c}\text { Silty } \\
\text { sand } \\
\left(30 \% F_{c}\right)\end{array}$ & $\begin{array}{c}\text { Silty } \\
\text { sand } \\
\left(40 \% F_{c}\right)\end{array}$ & $\begin{array}{c}\text { Silt } \\
\left(100 \% F_{c}\right)\end{array}$ \\
\hline \hline$F_{c}[\%]$ & 0 & 10 & 20 & 30 & 40 & 100 \\
\hline$G_{s}\left[\mathrm{~g} / \mathrm{cm}^{3}\right]$ & 2.670 & 2.672 & 2.674 & 2.676 & 2.679 & 2.690 \\
\hline$e_{\min }$ & 0.519 & 0.461 & 0.418 & 0.401 & 0.457 & 0.707 \\
\hline$e_{\max }$ & 0.844 & 0.791 & 0.753 & 0.727 & 0.744 & 1.429 \\
\hline$D_{10}$ & 0.350 & 0.130 & 0.050 & 0.020 & 0.010 & 0.0012 \\
\hline$D_{30}$ & 0.550 & 0.290 & 0.210 & 0.140 & 0.090 & 0.017 \\
\hline$D_{50}$ & 0.770 & 0.480 & 0.400 & 0.300 & 0.230 & 0.035 \\
\hline$D_{60}$ & 0.820 & 0.600 & 0.520 & 0.450 & 0.330 & 0.044 \\
\hline$C_{u}$ & 2.34 & 4.62 & 10.40 & 22.50 & 33.00 & 36.67 \\
\hline$C_{c}$ & 1.05 & 1.08 & 1.70 & 2.18 & 2.45 & 5.47 \\
\hline
\end{tabular}

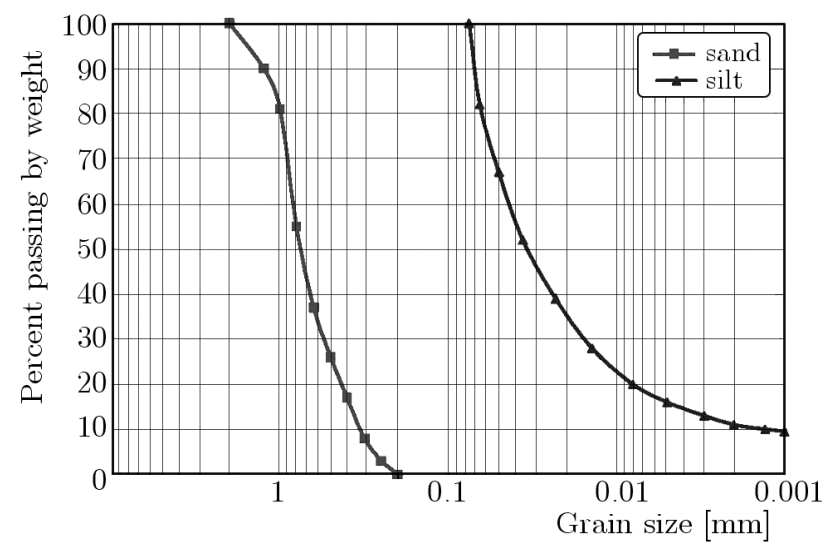

Fig. 1. Grain size distribution curves of tested materials

The grain size distribution curves for all sand silt mixtures under investigation are illustrated in Fig. $1 . D_{i}$ corresponds to the soil diameter at which $i \%$ of the soil weight is finer. The plasticity index of the silt Ip is $5 \%, C_{u}$ and $C_{c}$ are the coefficients of uniformity and curvature respectively. According to ASTM D2487-11(2011) classification, the sand under study is poorly graded (SP), while the silt is inorganic (ML). $e_{\max }$ is the maximum void ratio (loosest density state) and $e_{\min }$ is the minimum void ratio (densest density state). The variation of $e_{\max }$ and $e_{\min }$ in term of the fines content $F_{c}$ is shown in Fig. 2. It can be clearly seen that the variation of both indices follows the same trend. The two indices decrease with the increase of the fines content till $30 \%$, then they increase after this value. 


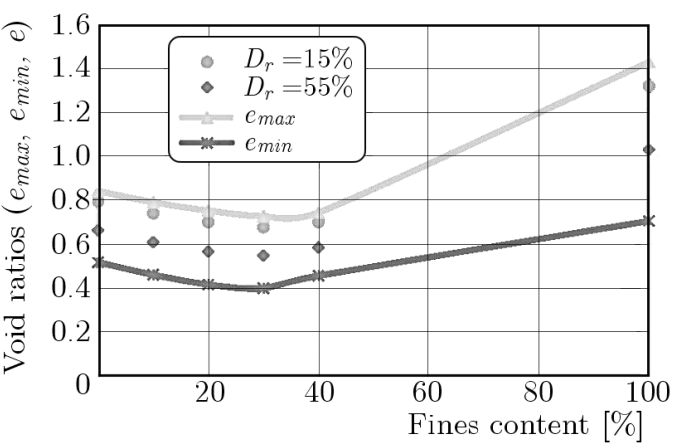

Fig. 2. Extreme and global void ratios of samples for different relative densities versus fines content

\section{Laboratory experiment procedures}

\subsection{Preparation method}

Sample preparation methods affect considerably the liquefaction behaviour of soils (Ladd (1974), Mulilis et al. (1977). The sample under testing must be prepared in such a way to replicate the soil conditions at the field. Therefore the choice of a proper sample preparation method technique is important to determine the liquefaction potential of sandy soils. Numerous sample reconstitution methods have been elaborated for use in the laboratory, such as moist tamping, dry funnel pluviation and water sedimentation. The dry pluviation deposition method tends to reproduce well the field performance as shown by Vaid et al. (1999). In this present study, the dry funnel pluviation is used as a sample preparation method in order to reproduce the soil conditions at the field. The experimental device fabricated for the dry funnel depositional method is shown in Fig. 3.

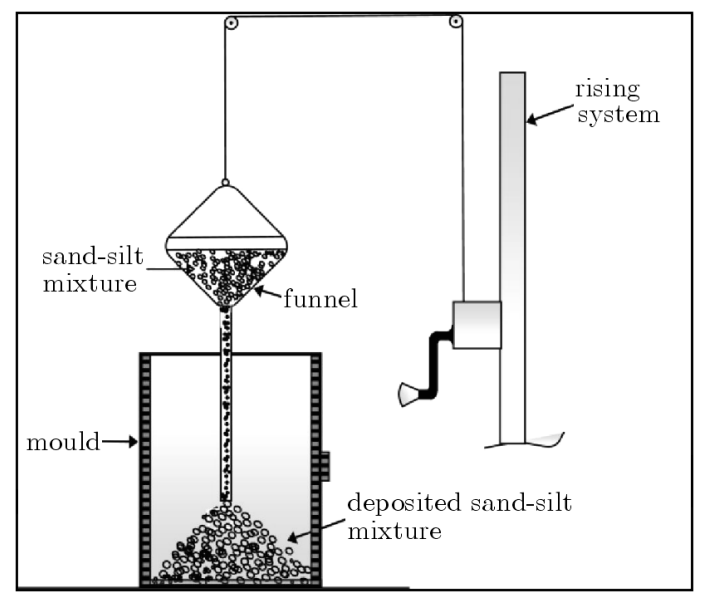

Fig. 3. Dry funnel deposition system

\subsection{Soil sample preparation}

Dry sand and silt have been mixed according to the considered different weight ratios. The samples hwve been prepared by means of a mould consisting of two semi-cylindrical shells (Fig. 4). The two parts of the mould can be easily joined by a hose clamp.

The samples are cylindrical in shape of $70 \mathrm{~mm}$ in diameter $D$ and $140 \mathrm{~mm}$ in height $H$ $(H / D=2.0)$. The mass of the sand-silt mixture to be put inside the mould is calculated according to the required relative density (initial volume is known). The relative density of the sample is defined as 


$$
D_{r}=\frac{e_{\max }-e}{e_{\max }-e_{\min }}
$$

The testings have been carried out on reconstituted saturated samples.

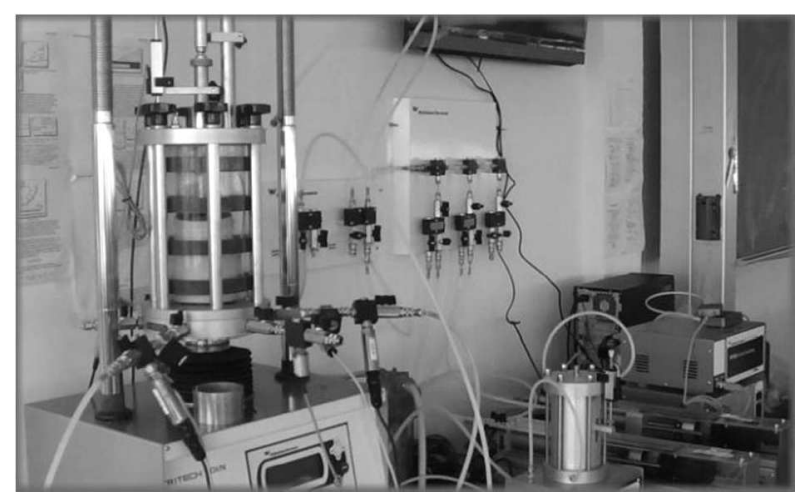

Fig. 4. Experiment device

\subsection{Degree of saturation during the test}

Firstly, the samples have been purged by carbon dioxide gas for more than 30 minutes, and then saturated by de-aired water. Skempton's pore water parameter $B$ controls the saturation state. According to ASTM D 4767-02 (2004), the samples can be considered fully saturated if $B$ is at least or greater than 0.95 . In all the undrained tests, this condition has been fulfilled. In order to achieve full saturation state, a backpressure of $100 \mathrm{kPa}$ has been applied during the test experiments in this investigation.

\subsection{Consolidation and loading}

Samples were isotropically consolidated at a mean effective stress of $100 \mathrm{kPa}$ and then subjected to undrained monotonic triaxial loading. A constant strain rate of $5 \%$ per hour was applied during all the tests in order to stabilize the pore water pressure built up throughout all the samples. All the tests were carried up to $25 \%$ axial strain.

\subsection{Estimation of the undrained critical shear strength}

The behaviour of saturated sand specimens in undrained triaxial test can be presented in Fig. 5 (Vaid and Chern, 1983). Points $A, B$, and $C$ represent compressed specimens isotropically. In undrained (constant volume) effective mean stress decreases as the excess pore water pressure develops. During this process, soil sample reaches peak undrained shear strength $S_{u}$ (yield) at positions $A_{1}, B_{1}, C_{1}$. Liquefaction is triggered when the shear stress applied on soil specimen attempts to exceed the peak shear strength as a result of static or dynamic loading. Beyond that, a strain softening develops in the specimen till the critical state is reached at point $D$ on CSL (critical state line). This position is called steady state.

If the effective stress path reaches the flow liquefaction surface (FLS), the soil element becomes unstable and its effective stress state rapidly moves to the steady-state, where the soil element undergoes sudden failure with large deformation.

In the undrained case, conventionally, the shear strength at steady state is the critical shear strength. In the framework of critical state soil mechanics theory, the following relationship can be written

$$
q_{s}=M p_{s}^{\prime}
$$


(a)

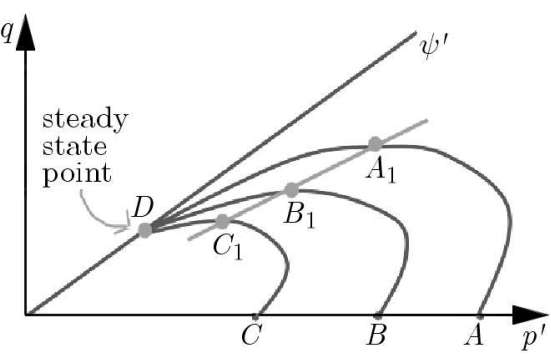

(b)

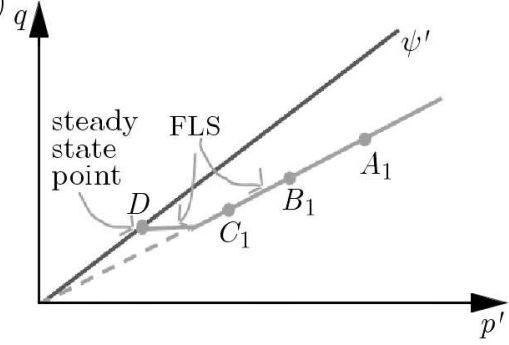

Fig. 5. Graphical explanation of Flow Liquefaction Surface (Vaid and Chern, 1983); (a) stress paths $\left(q-p^{\prime}\right)$ in undrained test, (b) flow liquefaction susceptibility

For triaxial tests, and according to Schofield and Wroth (1968), the mobilized angle of interparticle friction at the steady state $\phi_{s}$ can be defined as

$$
\sin \phi_{s}=\frac{3 M}{6+M}
$$

where $q_{s}$ and $p_{s}^{\prime}$ indicate the deviatoric stress $\left(\sigma_{1}^{\prime}-\sigma_{3}^{\prime}\right)$ and the effective mean principal stress $\left(\sigma_{1}^{\prime}+2 \sigma_{3}^{\prime}\right) / 3$, respectively. The critical shear strength $S_{\text {ucr }}$ will be

$$
S_{u c r}=\frac{q_{s}}{2} \cos \phi_{s}
$$

\section{Tests results and discussions}

The results of the undrained monotonic compression triaxial tests carried out for different fines content ranging from 0 to $40 \%$ at $100 \mathrm{kPa}$ mean confining pressure within two separate density ranges $\left(D_{r}=15\right.$ and 55\%) are shown in Figs. 6 to 10. During the tests both stress paths $\left(p^{\prime}, q\right)$ are recorded and represented graphically, as well as the axial strain versus the deviatoric stress $q$.

We note that for $F_{c}$ ranging from $0 \%$ to $30 \%$ that the critical deviatoric stress $q_{c r}$ is obtained for the axial strain ranging from $0.8 \%$ to $1.6 \%$ (Fig. 6), in which the fine fraction is $F_{c}=0 \%$, the two types of initial relative density $D_{r}=15 \%$ and $55 \%$, the critical deviatoric stresses $q_{c r}$ obtained are $34.12 \mathrm{kPa}$ and $38.69 \mathrm{kPa}$ corresponding to the effective mean stresses $p_{c r}^{\prime} 57.86 \mathrm{kPa}$ and $63.11 \mathrm{kPa}$ for the initial relative density $D_{r}=15 \%$ and $55 \%$, respectively $(M=0.84$, $\phi_{s}=21.62^{\circ}$.
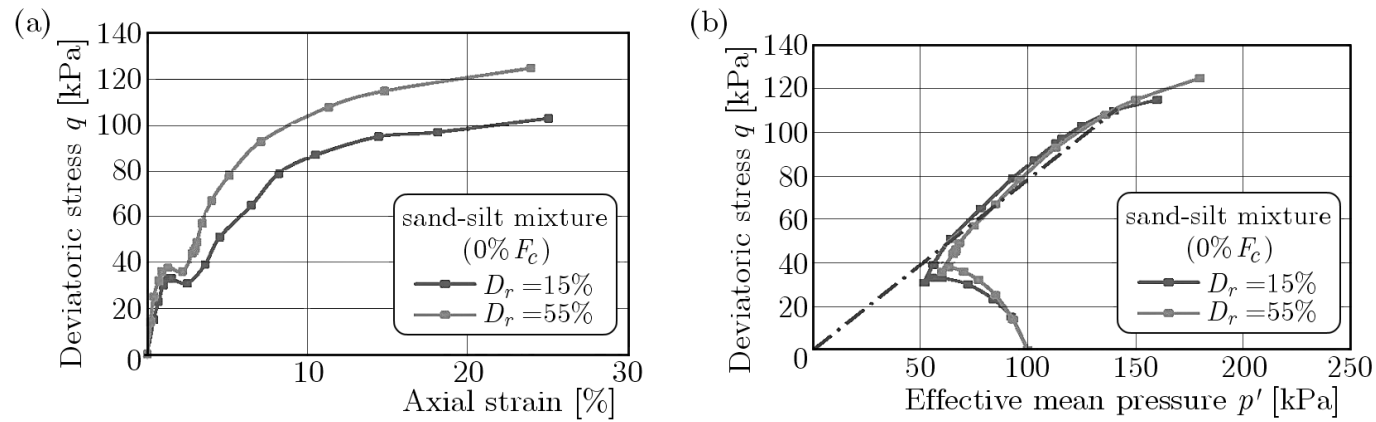

Fig. 6. (a) Test results of deviatoric stress versus axial strain $\left(q, \varepsilon_{a}\right), F_{c}=0 \%$, (b) stress paths $\left(q, p^{\prime}\right)$ for undrained loading tests, $F_{c}=0 \%$

When the fine fraction is $10 \%$ (Fig. 7), the critical deviatoric stresses $q_{c r}$ are $32.08 \mathrm{kPa}$ and $35.84 \mathrm{kPa}\left(M=0.83, \phi_{s}=21.38^{\circ}\right)$, respectively. For the case $F_{c}=20 \%$ (Fig. 8) $q_{c r}$ are $28.54 \mathrm{kPa}$ and $31.08 \mathrm{kPa}\left(M=0.82, \phi_{s}=21.14^{\circ}\right)$, respectively. For the case $F_{c}=30 \%$ (Fig. 9) $q_{c r}$ are $24.09 \mathrm{kPa}$ and $27.32 \mathrm{kPa}\left(M=0.80, \phi_{s}=20.67^{\circ}\right)$, respectively. 
(a)

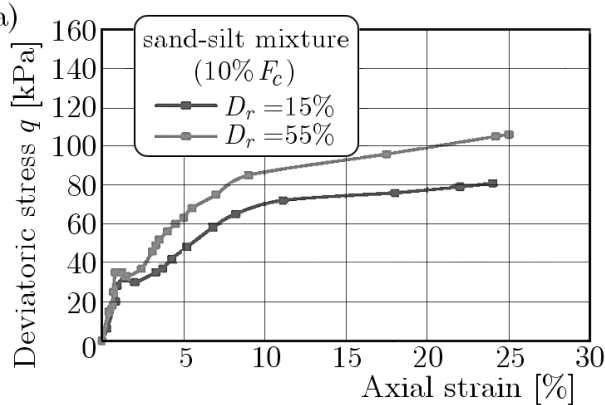

(b)

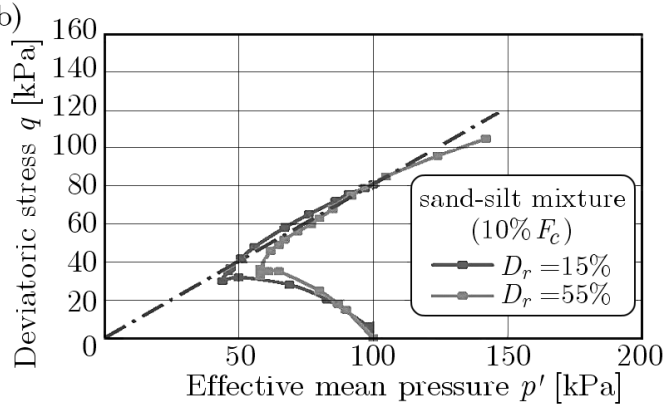

Fig. 7. (a) Test results of deviatoric stress versus axial strain $\left(q, \varepsilon_{a}\right), F_{c}=10 \%$, (b) stress paths $\left(q, p^{\prime}\right)$ for undrained loading tests, $F_{c}=10 \%$
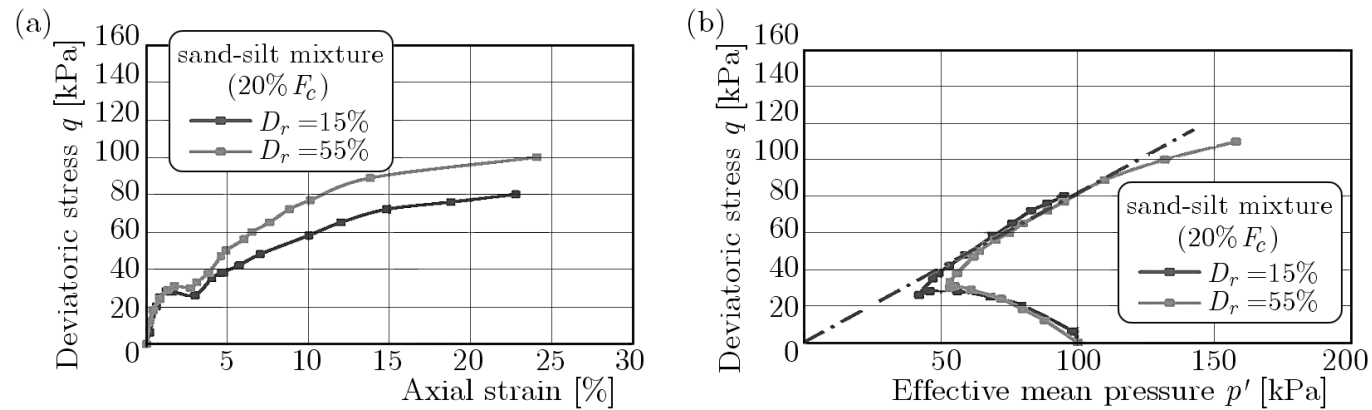

Fig. 8. (a) Test results of deviatoric stress versus axial strain $\left(q, \varepsilon_{a}\right), F_{c}=20 \%$, (b) stress paths $\left(q, p^{\prime}\right)$ for undrained loading tests, $F_{c}=20 \%$

(a)

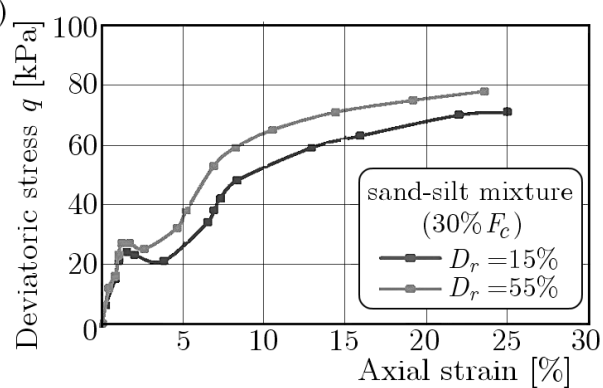

(b)

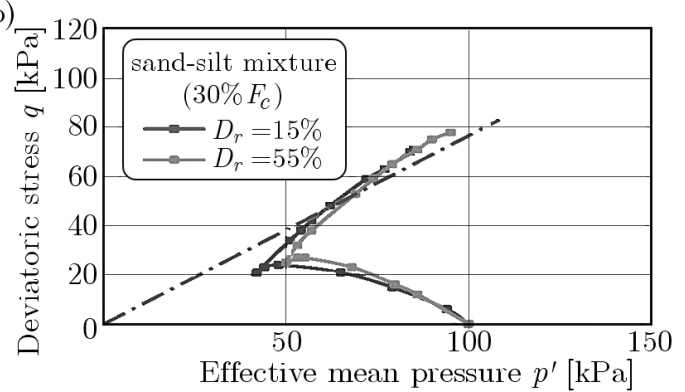

Fig. 9. (a) Test results of deviatoric stress versus axial strain $\left(q, \varepsilon_{a}\right), F_{c}=30 \%$, (b) stress paths $\left(q, p^{\prime}\right)$ for undrained loading tests, $F_{c}=30 \%$

While in the case of $F_{c}=40 \%$ (Fig. 10), we notice that the mixture exhibits dilatant behavior and does not develop a contractancy phase, and the deviatoric stress $q_{c r}$ increases continuously and has values of $27.52 \mathrm{kPa}$ and $30.85 \mathrm{kPa}$ for $D_{r}=15 \%$ and $55 \%$, respectively $(M=0.78$, $\phi_{s}=20.19^{\circ}$.

We notice that an increase in the amount of fines of $0 \%$ to $30 \%$ leads to a decrease in the deviatoric stress. This decrease comes from the role of the fines in reducing the soil dilatancy and amplifying the phase of contractancy of the sand-silt mixtures, leading to a reduction in the confining effective pressure and consequently to a decrease in the peak strength of the mixtures. The stress path in the $\left(p^{\prime}, q\right)$ plane shows clearly the role of the fines in the decrease in the average effective pressure and the maximum deviatoric stress (Figs. 6b-10b). In this case, the effect of fines on the undrained behaviour of the mixtures is observed for a lower fines contents of $30 \%$. These results are in good agreement with the observations of Shen et al. (1977), Troncoso and Verdugo (1985), Koester (1994) and Kokusho et al. (2014).

When the amount of the fine is $40 \%$, there is an increase in the deviatoric stress, and this increase is due to the role of the fine to increase the dilatancy in the soil and the absence of the 
(a)

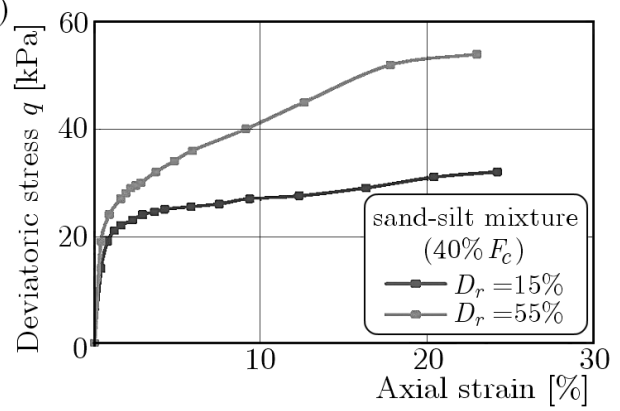

(b)

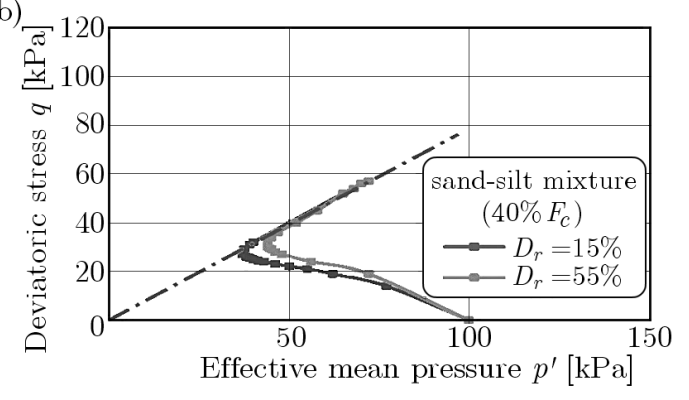

Fig. 10. (a) Test results of deviatoric stress versus axial strain $\left(q, \varepsilon_{a}\right), F_{c}=40 \%$, (b) stress paths $\left(q, p^{\prime}\right)$ for undrained loading tests, $F_{c}=40 \%$

contractancy phase. This shows that beyond $30 \%$ of the fines content, the fines participate in the strength of the mixture and reverse the behaviour trend. Table 2 presents the summary of the undrained monotonic compression triaxial tests.

Table 2. Undrained monotonic test results for different initial relative densities of sand-silt mixtures

\begin{tabular}{|l|c|c|c|c|c|c|c|c|c|}
\hline & $F_{c}[\%]$ & $e$ & $e *$ & $e_{\min }^{*}$ & $e_{\max }^{*}$ & $D_{r}[\%]$ & $D_{r}^{*}[\%]$ & $M$ & $S_{u c r} / \sigma_{c}$ \\
\hline \hline $\begin{array}{l}\text { Clean sand } \\
\left(0 \% F_{c}\right)\end{array}$ & $0 \%$ & 0.795 & 0.795 & 0.519 & 0.844 & $15 \%$ & $15 \%$ & 0.84 & 0.1615 \\
\hline & & 0.665 & 0.665 & 0.519 & 0.844 & $55 \%$ & $55 \%$ & 0.84 & 0.1811 \\
\hline $\begin{array}{l}\text { Silty sand } \\
\left(10 \% F_{c}\right)\end{array}$ & $10 \%$ & 0.742 & 0.897 & 0.591 & 0.951 & $15 \%$ & $-16.26 \%$ & 0.83 & 0.1506 \\
\hline & & 0.610 & 0.753 & 0.591 & 0.951 & $55 \%$ & $27.98 \%$ & 0.83 & 0.1682 \\
\hline $\begin{array}{l}\text { Silty sand } \\
\left(20 \% F_{c}\right)\end{array}$ & $20 \%$ & 0.703 & 0.978 & 0.648 & 1.037 & $15 \%$ & $-41.34 \%$ & 0.82 & 0.1347 \\
\cline { 3 - 10 } $\begin{array}{l}\text { Silty Sand } \\
\left(30 \% F_{c}\right)\end{array}$ & \multirow{2}{*}{$30 \%$} & 0.569 & 0.823 & 0.648 & 1.037 & $55 \%$ & $6.56 \%$ & 0.82 & 0.1466 \\
\hline $\begin{array}{l}\text { Silty Sand } \\
\left(40 \% F_{c}\right)\end{array}$ & $40 \%$ & 0.548 & 0.892 & 0.712 & 1.111 & $55 \%$ & $-14.62 \%$ & 0.80 & 0.11303 \\
\cline { 3 - 9 } & & 0.586 & 1.167 & 0.856 & 1.222 & $15 \%$ & $-99.38 \%$ & 0.78 & 0.1288 \\
\hline
\end{tabular}

This means that the soil under investigation exceeds the threshold set by the Chinese criteria (Wang, 1979), and the test results clearly show that the soil under study is susceptible to liquefy at a rate of $30 \%$ of fines. These results coincide with the actual observations in the three recent earthquakes, Northridge (1994), Kocaeli (1999), and Chi-Chi (1999) earthquakes, all of these showed signs of liquefaction in soils with greater than $15 \%$ of the fines content. This means the soils did not meet all the three of Chinese criteria, and yet still liquefied. The same observations are noticed in the case of static liquefaction failure catastrophic events reported by Kramer and Seed (1988), Fourie and Tshabalala (2005), in which post-liquefied soil has more than $20 \%$ of the silty fine content.

In this context, Holzer et al. (1999) noted that soils which would have been determined safe from liquefaction by the Chinese criteria did in fact liquefy and led to permanent ground deformations. Consequently, many recent researchers, such as Bray and Sancio (2006), Boulanger and Idriss (2006) recommended not relying on the Chinese criteria.

\subsection{Correlation of the critical undrained shear resistance $S_{u c r}$ and the equivalent void ratio $e^{*}$}

In equation (1.1), the fines particles are simply supposed to be occupying voids in the sand skeleton. The concept of the intergranular void ratio suggests that the fines fill the voids formed between the sand grains and thus the behaviour of sand with moderate amount of fines should 
be governed by the intergranular void ratio instead of the global void ratio. However, when the intergranular void ratio exceeds the maximum void ratio of the clean sand, there are sufficient fines to prevent grain-to-grain contact of the sand particles. In this case, the fines constitute the dominant structure and carry the shear forces while the coarse grains may act as reinforcing elements (Thevanayagam and Mohan, 2000). Zlatovic and Ishihara (1995) and Pitman et al. (1994) reported that fines particles started to come in between sand particle contacts at $5 \%$ fines content, and the sand particle contacts vanished completely at around $25 \%$ silt content. In order to satisfy these experimental observations (Thevanayagam et al., 2002), expression (1.1) was modified in the form of equation (1.2).

Generally, $e^{*}$ is obtained from correlation between soil grading properties and back-analysed values (Ni et al., 2004; Yang et al., 2006). Then, Rahman et al. (2008) analysed the experimental data of McGeary (1961) on binary packing studies and concluded that it should be dependent on both the particles size ratio $r$ and fines content $F_{c}$. The size ratio $r$ is defined by $r=$ $D_{50 \text { (fine) }} / D_{10 \text { (sand) }}$, where $D_{50 \text { (fine) }}$ is the median size of fines and $D_{10 \text { (sand) }}$ is the particle size at $10 \%$ fraction for host sand. The correlation was suggested in the present form

$$
\alpha=1-\left[1-\exp \left(-\frac{0.3}{k} \frac{F_{c}}{F_{\text {thre }}}\right)\right]\left(\frac{r F_{\text {thre }}}{F_{c}}\right)^{r}
$$

where $k=1-\sqrt[4]{r}, F_{\text {thre }}$ is threshold fines content or transitional fines content, which is characterized by the predominance of fines behaviour.

Thus, the value of $F_{\text {thre }}$ is defined by the point where the behaviour trend reverses with a further increase in the fines content. From our tests, this transition point is located at $30 \%$ fines content for all two initial relative densities as shown in Figs. 6b to 10b. For the studied sand-silt mixture, $r$ and $k$ are calculated to be: $r=0.100$ and $k=0.438$.

The variation in the equivalent void ratios versus the fines content for the initial relative densities $\left(D_{r}=15\right.$ and $\left.55 \%\right)$ is shown in Fig. 11.

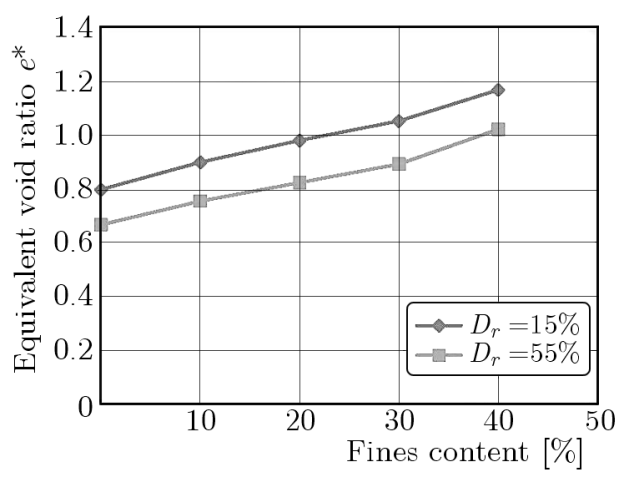

Fig. 11. Variation of the equivalent void ratio $e^{*}$ versus the fine content $F_{c}$

For all studied initial relative densities, it can be seen that a decrease in the global void ratio generates an increase in the equivalent or intergranular void ratio. The absolute rate of variation in both void ratios tends to decrease as long as the fines content increases.

Figure 12 shows the undrained critical shear strength variation versus the equivalent void ratio for the initial relative densities $\left(D_{r}=15\right.$ and 55\%). It is obvious from this that the undrained critical shear strength decreases linearly as the equivalent void ratio decreases and the fines content increases for all densities $\left(D_{r}=15\right.$ and 55\% during reconstitution) up to $30 \%$ fines content. It means that when decreasing the global void ratio and increasing the fines content, the undrained critical shear strength also decreases. It can he concluded that the global void ratio does not represent the real behaviour of silty sand soil with $0-30 \%$ fines content. Moreover, the equivalent void ratio is a key parameter for characterizing the mechanical state of clean sand as well as sand-silt mixtures. 


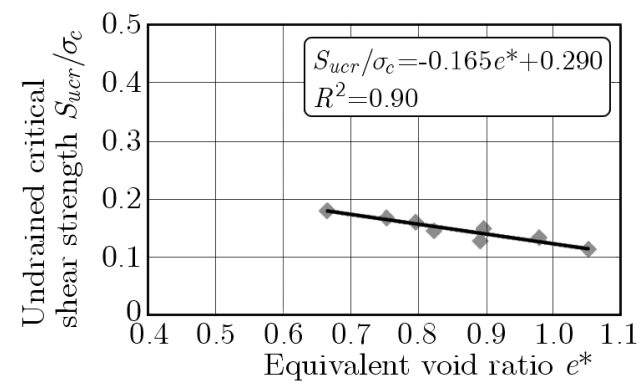

Fig. 12. Variation of the undrained critical shear strength versus the equivalent void ratio $e^{*}$ with

$$
\sigma_{c}=100 \mathrm{kPa}
$$

The following linear correlation of the normalized undrained shear strength and the equivalent intergranular void ratio is obtained

$$
\frac{S_{u c r}}{\sigma_{c}}=-0.165 e^{*}+0.290
$$

\subsection{Correlation of the critical undrained shear resistance $S_{u c r}$ and equivalent relative density $D_{r}^{*}$}

Since the equivalent intergranular void ratio $e^{*}$ is introduced as an essential representative parameter, consequently, the equivalent relative density should be defined as (Thevanayagam et al., 2002, 2003; Shenthan, 2005)

$$
D_{r}^{*}=\frac{e_{\max , c s}-e^{*}}{e_{\max , c s}-e_{\min , c s}} \cdot 100
$$

where $e_{\max , c s}$ is the maximum void ratio of clean sand and $e_{\text {min,cs }}$ is the minimum void ratio of clean sand. This relative index compares the equivalent granular state of sandy soils with two extreme density states of clean sand.

Figure 13 shows the variation of the normalized undrained critical shear strength in terms of the equivalent relative density. A linear relationship is obtained as

$$
\frac{S_{u c r}}{\sigma_{c}}=0.0537 d_{r}^{*}+0.1506
$$

where $d_{r}^{*}$ is the relative density expressed as a decimal, $d_{r}^{*}=D_{r}^{*} / 100$.

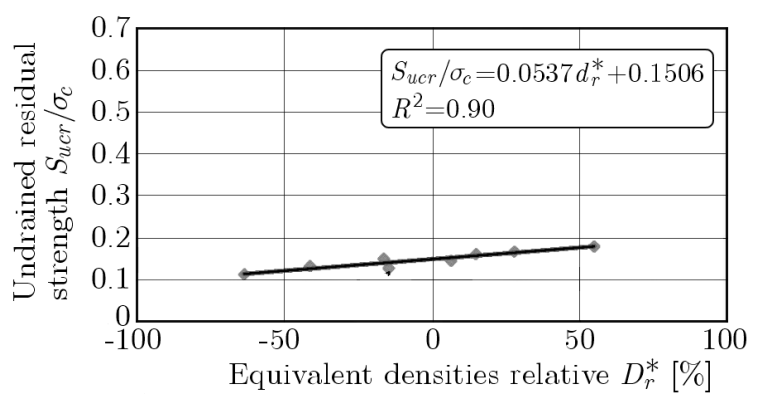

Fig. 13. Undrained critical shear strength versus the equivalent relative density with $\sigma_{c}=100 \mathrm{kPa}$

The critical undrained shear strength increases with the increase in the equivalent relative density for $F_{c} \leqslant 30 \%$. In the range $0-30 \%$ of the fines content, for both relationships obtained, we may deduce that the equivalent intergranular void ratio and the equivalent relative density are key parameters to characterize the susceptibility of instability of such soils. 


\section{Conclusions}

A series of monotonic undrained triaxial tests have been undertaken on a reconstituted saturated sand-silt mixtures specimen. Two levels of the initial relative density (15 and 55\%) with initial effective confining stress of $100 \mathrm{kPa}$ were used in the experimental program. The range (0 to $40 \%$ ) of fines content constitutes the sand-silt mixtures forming the soil samples.

In the framework of the steady state concept and liquefaction susceptibility of sands and, in the present undrained triaxial tests under monotonic loadings, the present sand-silt mixtures may experience limited liquefaction behavior and dilation.

The obtained result shows that the critical undrained shear strength is considerably affected by the fraction of fines contained in the sand matrix. The participation of silty fines in the force chain skeleton of the soil depends on their content. Consequently, the equivalent intergranular void ratio has been introduced to express the fine participation. For our case, such a parameter is valid till $30 \%$ to represent our soil. The advantage of this parameter may be able to define the inter-grain friction properties of sand-silt mixtures.

The critical undrained shear strength decreases in a linear manner with an increase in the equivalent intergranular void ratio, while it increases with the increase of the equivalent relative density, this behaviour is valid for $F_{c} \leqslant 30 \%$ only. However, the factor $\alpha$ should be related to the mechanical parameters of sand silt mixtures via the critical state soil mechanics framework.

In the range 0-30\% of the fines content, for both relationships obtained, we may deduce that the equivalent intergranular void ratio and the equivalent relative density are key parameters to characterize the susceptibility of instability of such soils.

Moreover, this means that the soil under study exceeds the threshold set by the Chinese criteria (Wang, 1979) and the test results clearly show that this soil is susceptible to liquefy at a rate of $30 \%$ of the fines.

These results coincide with recent observations noticed in the case of static and cyclic liquefaction failures causing catastrophic events reported by many researchers.

\section{References}

1. ASTM D2487-11, 2011, Standard Practice for Classification of Soils for Engineering Purposes (Unified Soil Classification System), ASTM International, West Conshohocken, PA. DOI: 10.1520/D2487-11

2. ASTM D4767-02, 2004, Standard test method for consolidated undrained triaxial compression test for cohesive soils, American Society for Testing and Materials, Vol. 04.08, pp. 1-13

3. Boulanger R.W., IdRiss I.M., 2006, Liquefaction susceptibility criteria for silts and clays, Journal of Geotechnical And Geoenvironmental Engineering, 132, 11, 1413-1426, doi.org/10.1061/(ASCE)1090-0241(2006)132:11(1413)

4. Bray J.D., SANCIO R.B., 2006, Assessment of the liquefaction susceptibility of finegrained soils, Journal of Geotechnical and Geoenvironmental Engineering, 132, 9, 1165-1177, doi.org/10.1061/(ASCE)1090-0241(2006)132:9(1165)

5. Chang N.Y., Yeh S.T., Kaufman L.P., 1982, Liquefaction potential of clean and silty sands, Proceedings of the Third International Earthquake Microzonation Conference, 2, 1017-1032

6. Fourie A.B., Tshabalala L., 2005, Initiation of static liquefaction and the role of K0 consolidation, Canadian Geotechnical Journal, 42, 3, 892-906, dx.doi.org/10.1139/t05-026

7. Holzer T.L., Bennett M.J., Ponti D.J., Tinsley III J.C., 1999, Liquefaction and soil failure during 1994 Northridge earthquake, Journal of Geotechnical and Geoenvironmental Engineering, 125, 6, 438-452, doi.org/10.1061/(ASCE)1090-0241(1999)125:6(438) 
8. Ishihara K., 1993, Liquefaction and flow failure during earthquakes, Geotechnique, 43, 3, 351-415, icevirtuallibrary.com/content/article/10.1680/geot.1993.43.3.351

9. Koester J.P., 1994, The influence of fines type and content on cyclic strength, Ground Failures under Seismic Conditions, ASCE, 17-33

10. Kokusho T., Nagao Y., Ito F., Fukuyama T., 2014, Sand liquefaction observed during recent earthquake and basic laboratory studies on aging effect, Earthquake Geotechnical Engineering Design, 75-92, Springer International Publishing. doi: 10.1007/978-3-319-03182-8_3

11. Kramer S.L., Seed H.B., 1988, Initiation of soil liquefaction under static loading conditions, Journal of Geotechnical Engineering, 114, 4, 412-430, dx.doi.org/10.1061/(ASCE)07339410(1988)114:4(412)

12. LADD R.S., 1974, Specimen preparation and liquefaction of sands, Journal of the Geotechnical Engineering Division, 100, 10, 1180-1184

13. Maheshwari B.K., Patel A.K., 2010, Effects of non-plastic silts on liquefaction potential of Solani sand, Geotechnical and Geological Engineering, 28, 5, 559-566, doi.org/10.1007/s10706-0109310-z

14. MCGEARY R.K., 1961, Mechanical packing of spherical particles, Journal of the American Ceramic Society, 44, 10, 513-522, dx.doi.org/10.1111/j.1151-2916.1961.tb13716.x

15. Mulilis J.P., Arulanandan K., Mitchell J.K., Chan C.K., Seed H.B., 1977, Effects of sample preparation on sand liquefaction, Journal of the Geotechnical Engineering Division, 103, 2, 91-108

16. Ni Q., Tan T.S., Dasari G.R., Hight D.W., 2004, Contribution of fines to the compressive strength of mixed soils, Geotechnique, 54, 9, 561-569, refdoc.fr/Detailnotice?idarticle=8461334

17. Olson S., Stark T., 2003, Yield strength ratio and liquefaction analysis of slopes and embankments, Journal of Geotechnical and Geoenvironmental Engineering, 129, 8, 727-737, doi.org/10.1061/(ASCE)1090-0241(2003)129:8(727)

18. Pitman T.D., Robertson P.K., Sego D.C., 1994, Influence of fines on the collapse of loose sands, Canadian Geotechnical Journal, 31, 5, 728-739, doi/abs/10.1139/t94-084

19. Prakash S., Puri V.K., 2010, Recent advances in liquefaction of fine grained soils, 5th International Conference on Recent Advances in Geotechnical Earthquake Engineering and Soil Dynamics, San Diego, California, 1-6

20. Rahman M.M., Lo S.R., Gnanendran C.T., 2008, On equivalent granular void ratio and steady state behaviour of loose sand with fines, Canadian Geotechnical Journal, 45, 10, 1439-1455, dx.doi.org/10.1139/T08-064

21. Schofield A., Wroth P., 1968, Critical State Soil Mechanics, London, McGraw-Hill

22. Seed H.B., Idriss I.M., Arango I., 1983, Evaluation of liquefaction potential using field performance data, Journal of Geotechnical Engineering, 109, 3, 458-482, doi.org/10.1061/(ASCE)07339410(1983)109:3(458)

23. Shen C.K., Vrymoed J.L., Uyeno C.K., 1977, The effects of fines on liquefaction of sands, Proceedings of 9th International Conference on Soil Mechanics and Foundation Engineering, Tokyo, 381-385

24. Shenthan T., 2005, Liquefaction mitigation in silty soils using composite stone column, Ph.D. Dissertation, University at Buffalo, Buffalo, NY

25. Thevanayagam S., Mohan S., 2000, Intergranular state variables and stress-strain behaviour of silty sands, Geotechnique, 50, 1, 1-23, doi:10.1680/geot.2000.50.1.1

26. Thevanayagam S., Shenthan T., Kanagalingam T., 2003, Role of Intergranular Contacts on Mechanisms Causing Liquefaction and Slope Failures in Silty Sands, Final Report, USGS Award No. 01HQGR0032 and 99HQGR0021. U.S. Geological Survey, Department of the Interior, Reston, $\mathrm{Va}$ 
27. Thevanayagam S., Shenthan T., Mohan S., Liang J., 2002, Undrained fragility of clean sands, silty sands, and sandy silts, Journal of Geotechnical and Geoenvironmental Engineering, 128, 10, 849-859

28. Troncoso J.H., Verdugo R., 1985, Silt content and dynamic behavior of tailing sands, Proceedings of XI International Conference on Soil Mechanics and Foundation Engineering, 1311-1314

29. VAID Y.P., 1994, Liquefaction of silty soils, Ground Failures under Seismic Conditions. Geotechnical Special Publication, 44, American Society of Civil Engineers, 1-16

30. VAID Y.P., Chern J.C., 1983, Mechanism of deformation during cyclic undrained loading of saturated sands, International Journal of Soil Dynamics and Earthquake Engineering, 2, 3, 171177, doi.org/10.1016/0261-7277 (83) 90014-1

31. Vaid Y.P., Sivathayalan S., Stedman D., 1999, Influence of specimen-reconstituting method on the undrained response of sand, ASTM Geotechnical Testing Journal, 22, 3, 187-195, refdoc.fr /Detailnotice?idarticle $=11381016$

32. WANG W.S., 1979, Some findings in soil liquefaction, Water Conservancy and Hydroelectric Power Scientific Research Institute, Beijing, China

33. Yamamuro J.A., Kelly M.C., 2001, Monotonic and cyclic liquefaction of very loose sands with high silt content, Journal of Geotechnical and Geoenvironmental Engineering, 127, 4, 314-324, doi.org/10.1061/(ASCE)1090-0241(2001)127:4(314)

34. Yamamuro J.A., Lade P.V., 1997, Static liquefaction of very loose sands, Canadian Geotechnical Journal, 34, 6, 905-917, doi.org/10.1139/t97-057

35. Yamamuro J.A., Lade P.V., 1998, Steady-state concepts and static liquefaction of silty sands, Journal of Geotechnical and Geoenvironmental Engineering, 124, 9, 868-877, doi.org/10.1061/(ASCE)1090-0241(1998)124:9(868)

36. Yang S.L., Lacasse S., SAndven R.F., 2006, Determination of the transitional fines content of mixtures of sand and non plastic fines, Geotechnical Testing Journal, 29, 2, 102-107, hrefdoc.fr/Detailnotice?idarticle $=6662871$

37. Zlatovic S., Ishinara K., 1995, On the influence of non-plastic fines on residual strength, Proceedings of the First International Conference on Earthquake Geotechnical Engineering, Tokyo, 14-16 